\title{
INTERPRETING STUDIES: A CRITICAL VIEW FROM WITHIN
}

\author{
Daniel Gile \\ ESIT, Université Paris 3 - Sorbonne Nouvelle
}

\begin{abstract}
The paper describes and discusses the historical evolution of IS from a professiondriven, narrow-focused independent entity towards a wider academic discipline addressing all types of interpreting within the discipline of Translation Studies (TS). It explains its limitations and weaknesses in terms of size, environmental factors and human factors. It discusses the effects of the integration of IS into TS and concludes with a few suggestions to IS leaders in view to strengthen the discipline.

\section{Resumen}

El presente artículo describe y analiza la evolución histórica de los Estudios de Interpretación, que pasan de ser una entidad independiente de miras estrechas e impulsada por consideraciones profesionales a configurarse como una disciplina académica más amplia, que aborda todo tipo de interpretación en el ámbito de los Estudios de Traducción. En el texto se explican sus limitaciones y puntos débiles en términos de tamaño, factores infraestructurales y humanos, al tiempo que se trata el efecto de su integración en el marco de los Estudios de Traducción. El artículo concluye con una serie de sugerencias para la consolidación de la disciplina dirigidas a los responsables en este ámbito.
\end{abstract}

Keywords: Interpreting studies. Research history. Achievements. Limitations. Research quality. Empirical Science Paradigm. Liberal Arts Paradigm.

Palabras clave: Estudios de interpretación. Historia de la investigación. Logros. Limitaciones. Calidad investigadora. Paradigma empírico analítico. Paradigma humanista. 


\section{Introduction: the birth and early stages of an interpreting research discipline}

Reflection and research about translation probably started with introspection by practitioners before it was taken up by theologians, philosophers and other thinkers and then by linguists. It ultimately crystallized as the Translation Studies discipline in the 1970s, but the roots of TS can be traced back to early history and when it was established as a discipline, it already had a substantial body of personalities and texts to refer to.

Reflection on interpreting per se started much later, in the second half of the $20^{\text {th }}$ century. It also started with introspection but, contrary to translation, it bypassed philosophical and other more intellectual reflection and very rapidly focused on professional and training issues, whereas in translation research, both were and have remained only two of many foci of interest of translation scholars. Actually, while there were publications on interpreting in various parts of the world from the 1960s on, in particular in Japan, where practical books and papers were published (see Gile 1988), and in the USSR, where research was undertaken in cooperation with psycholinguists which did not reach the West (see Setton's and Ivanova's editorial comments in Chernov 2004), it is probably fair to say that the emergence of a discipline devoted to interpreting research in the 1970s is due to a large extent to the ambition and leadership of Danica Seleskovitch of Paris. Seleskovitch set up at ESIT the first doctoral program devoted to translation and interpreting in France, one of the very first in Europe, and strongly encouraged interpreters to do research on interpreting. Judging by the CIRIN bibliography (www.cirinandgile.com), the pattern of productivity in publications for the two main centres of research from the 1950s through the 1990s looks as shown in table 1 , and inaccurate as it may be with respect to the USSR because of a lack of access to the literature in Russian, it shows a spectacular development from

\begin{tabular}{|l|l|l|l|l|l|}
\hline & $1950 \mathrm{~s}$ & $1960 \mathrm{~s}$ & $1970 \mathrm{~s}$ & $1980 \mathrm{~s}$ & $1990 \mathrm{~s}$ \\
\hline $\begin{array}{l}\text { ESIT publications } \\
\text { PhDs }\end{array}$ & 0 & $4(7.1 \%)$ & $\begin{array}{l}31(16.5 \%) \\
5(71.4 \%)\end{array}$ & $\begin{array}{l}53(10.5 \%) \\
3(17.6 \%)\end{array}$ & $\begin{array}{l}36(1.8 \%) \\
2(7.7 \%)\end{array}$ \\
\hline USSR/Russia publications & 2 & 7 & 17 & 8 & 20 \\
\hline $\begin{array}{l}\text { Total number of } \\
\text { publications worldwide } \\
\text { PhDs }\end{array}$ & 39 & 56 & 187 & 506 & 1997 \\
\end{tabular}

Table 1: General development patterns in published text production from ESIT vs. the USSR/Russia and the total production worldwide from the 1950s through the1990s. Percentages refer to total production worldwide (source: CIRIN database). 
ESIT. During the 1970s, 5 doctoral dissertations on interpreting were defended at ESIT out of a total of 7 worldwide. Subsequently, as explained below, the 'Paris school' lost much of its influence in research, but it had given the initial impetus which allowed the discipline to emerge.

Qualitatively, the initial direction of the new discipline could be characterized as follows:

1. It addressed exclusively conference interpreting and was engaged in by conference interpreters. Seleskovitch was a central personality in AIIC, the International Association of Conference Interpreters, and ESIT trained exclusively conference interpreters (and translators).

2. It was built around a model of interpreting initially developed by Seleskovitch under the name théorie du sens ('theory of sense'), later renamed "Interpretive theory of translation", with no reference to existing theories or models on/of Translation (used with a capital $\mathrm{T}$, the term refers here to both written translation and interpreting).

3. It was exclusive. Not only did it focus almost solely on interpreter training and on the 'theory of sense' as an explanation of the interpreting process, but it deliberately excluded psychological research (despite occasional references to Piaget) and linguistics (see for example Seleskovitch 1984) as well as research work done on interpreting elsewhere, including the USSR and EastEuropean countries, studies done by psycholinguists in the 1960s and 1970s and research on written translation (there are virtually no references to such publications in the publications of ESIT authors at least until the late 1980s).

4. It was prescriptive, and for justification, it relied mostly on introspection and on persuasion by illustration from the interpreters' daily practice and from the interpreting classroom. Experimental research was banned for lacking ecological validity.

Thus, in the 1970s, the budding discipline was profession-driven, profession-oriented and exclusive, in other words atypical for an academic discipline, while during the same period, the budding Translation Studies discipline, which was developing from within academia rather than from within professional circles, was academic and theory-oriented.

\section{The context of a change of paradigm}

The ideas developed by Seleskovitch and others at ESIT have remained influential as a basis for training - they are still cited frequently in papers on training - but as a research paradigm, their influence started to wane rapidly in the 1990s. This was brought about by a number of factors: 
a. Internal pressure:

More interpreters with interest in research and different views on theory and methodology, and in particular with aspirations in the direction of more 'scientific' work in the sense of empirical science and of interdisciplinarity, became aware of and were stimulated by each other's work. A milestone event in this development was a conference on interpreter training organized by the School for translators and interpreters of Trieste (Italy) in November 1986, where interpreting trainers from many schools met and aired ideas not always in line with the prevailing ESIT paradigm (Gran \& Dodds 1989).

b. Environmental stimulation:

In the 1990s, TS developed considerably, and conferences and colloquia started to multiply in universities with translator and interpreter training programs. This was helped by the creation of many new such programs in various European countries and by the 'academization' of existing programs, whereby besides training in Translation skills, there were requirements for research (and increasingly for doctoral work) from instructors, and sometimes from students. Such changes provided stimulation and motivation to interpreter trainers as well.

c. Self-limitation within the 'theory of sense' paradigm:

In terms of research, the 'interpretive paradigm' produced little after the 1980s, perhaps because all the essential points had already been made and followers of this paradigm did not wish to engage in interdisciplinary work or in experimental testing of the underlying hypotheses and of corollaries. The relative loss of influence in favour of other approaches which offered better opportunities for innovation was therefore natural.

\section{Interpreting research in the 1990s}

The 1990s marked a new era in research into interpreting in several ways.

Firstly, the population structure of authors engaged in such research changed. In the 1980s, according to the CIRIN database, out of a total of 267 authors, only 15 wrote at least 5 publications over the decade (one every other year), and out of these, 5 (33\%) were ESIT authors (their publications accounted for a bit less than $10 \%$ of the total production worldwide); most of the other (relatively) prolific authors were members of AIIC, the International Association of Conference Interpreters, who adopted similar views about 
what interpreting should be like and how it was to be taught. In the 1990s, with a total of close to 2000 publications and 712 authors, 50 authors wrote at least 5 publications over the decade (more than 3 times the number of authors with the same minimum production in the 1980s). Only 2 of them were from ESIT, and their total production amounted to about $1 \%$ of the total production. Fifteen (relatively) prolific authors were from Italy (their total production accounted for $8 \%$ of the total production), 5 were from Japan, 3 from Denmark and 3 from Germany, and about 20 more came from other parts of the world including Austria, Bulgaria, China, The Czech Republic, Finland, Israel and Poland. Some of these authors came from a similar background as the influential authors of the 1980s - they were practicing AIIC conference interpreters with AIIC-inspired views - but others had different backgrounds.

These changes were made possible by improved communications in the Conference Interpreting Research community. In 1988, the SSLMIT Trieste launched The Interpreters' Newsletter, the first journal devoted to interpreting. In 1990, an international information network of research into interpreting, which later became CIRIN, was established with a national-Node structure to disseminate the information worldwide. With the rapid spreading of email and the Internet, communications became much more convenient and information and influence within the CIR community became highly decentralized. An important aspect of this decentralization resides in the fact that many of the new authors of the 1990s came not from an essentially professional training program as was the case of ESIT, but from within university departments which trained translators and interpreters (admittedly, not always at the same level of professional skills). This more academic environment tended to orient such research along more traditional lines than the direction taken by ESIT, with more theory and more references to existing relevant literature, in particular in linguistics and psychology.

During the 1990s, research into conference interpreting was strongly influenced by cognitive science, especially cognitive psychology and neurolinguistics. This included the import of concepts and theories from these disciplines, but also of research methods. Much emphasis was put on empirical research, and in particular on experimental research. The main research axes remained the same: the interpreting process, training and quality in interpreting were still central in the mind of investigators, though other issues including text-linguistic features of interpreting, prosody, the history of interpreting, etc. were tackled as well.

Meaningful links between translation research and interpreting research were also established towards the mid-1990s, mostly at the initiative 
of translation scholars who were open-minded enough to invite interpreting research scholars into their institutions (José Lambert, the initiator of the highly influential CE(T)RA program, was prominent among them). Rapidly, translation scholars and interpreting scholars started meeting regularly in Translation Studies conferences, working together in the same editorial and other committees and holding offices in the same TS organizations. The academization of translator and interpreter training programs in many countries has also helped familiarize interpreting students with translation theory before they even started working on their graduation theses. The effects of such links between IS (Interpreting Studies, as the discipline is called now) and the umbrella discipline TS are discussed in Section 6.

Much information on the development of the discipline from the beginnings and until the late 1990s can be found in Pöchhacker and Shlesinger's The Interpreting Studies Reader (2002) and in Pöchhacker's Introducing Interpreting Studies (2004), which provide evidence for the analyses in this section and elsewhere in the paper.

\section{Developments since the year 2000}

While a Kuhnian paradigm shift can be said to have occurred in the discipline between the 1980s and the 1990s, the evolution over the past decade or so has been substantial but shows no such discontinuity; changes seem to flow more smoothly as a result of what has become regular interaction between scholars.

Decentralization has continued, newcomers have entered the field (including authors from Korea and China). Moreover, there are now active research centres where several scholars interact regularly. In Italy, besides the pioneer Trieste, the Bologna University branch of SSLMIT in Forlì has developed spectacularly. In Spain, the University of Granada has a productive research team working on various aspects of interpreting quality and has already produced several doctoral dissertations (see the CIRIN Bulletins at www.cirinandgile.com) and a collective volume (Collados Aís et al. 2007). In Japan, JAIS (the Japan Association for Interpretation Studies) acts as a concentrator of research from numerous universities, especially with its journal Interpreting Research, the only Translation journal in Japan. This situation is very different from the situation in the 1980s, where the only interpreting research centre was ESIT, at least in the West.

The interaction between translation scholars and IS scholars has intensified over the past decade or so. Institutionally, as mentioned above, this is reflected in the participation of interpreting research personalities as office-holders in TS institutions such as journals, learned societies, scientific 
committees, but IS scholars also act as instructors in doctoral schools such as the CETRA program and the international doctoral program created at the University Rovira i Virgili in Tarragona (Spain) by Anthony Pym, to name just two examples.

A recent development of some importance has been the re-definition by an increasing number of IS scholars of the territory of IS to encompass forms of interpreting other than conference interpreting, more specifically various forms of public service interpreting (often referred to as 'community interpreting', which includes court interpreting, medical interpreting, police interpreting, etc.) and sign-language interpreting (which is partly public service interpreting and partly conference interpreting) - conference interpreting is no longer the central axis around which IS revolves.

This creates an interesting change: while nearly all investigators of interpreting until the end of the 1990s were practicing conference interpreters and interpreter trainers (see for instance Pöchhacker 1995), only some of the scholars who investigate public service interpreting are public service interpreters themselves. This dissociation between research and professional practice, which was frequent in written translation research (though many translation scholars have had at least some experience in professional translation), is new in Interpreting Studies. From the viewpoint of research, it has the advantage of allowing less subjective observation, description and analysis (see inter alia the warnings against practitioner bias in Stenzl 1983: 42 and Shlesinger 1989: 8), though the input of practitioners remains necessary in order to avoid the blatant mistakes of early investigators which were invoked by Seleskovitch to justify research on interpreting by professional interpreters.

Another positive change associated with the development of research into public service interpreting (PSIR) as part of IS is more openness to other disciplines beyond the cognitive sciences, and in particular linguistics (see for example Hale 2006, Mason 2006, Valero-Garcés 2006). Linguistics was not totally absent from research into conference interpreting either (see for instance Berselli et al. 2004), but PSIR gives it renewed impetus.

PSIR also involves much exploratory research into working conditions, the communication process during interpreting, professional qualifications, role perceptions and the effect of the interpreter's intervention on the parties concerned. This may have beneficial effects in two ways: Firstly, many of these projects are methodologically less sophisticated than experimental research and could encourage more IS scholars to engage in empirical research. Their studies could provide them with good basic hands-on training which could then lead to more ambitious designs. Secondly, most of these projects 
are directly relevant to the interpreters' needs and to their clients' needs, and could help bridge some of the perceived gap between research and practice and overcome some of the hostility of practitioners towards the academic world. Thus, as suggested by Garzone and Viezzi (2002: 5), the integration of PSIR into IS may turn out to be of paramount importance in the field - some authors like Rudvin (2006) believe that PSIR has already taken the lead.

\section{Interpreting Studies: A critical look from within}

Research into interpreting is now almost half a century old. From an embryonic state in the 1950s and 1960s, it developed into a viable entity in the1980s and 1990s. It now lives on the activity of a community of several dozen regular actors and hundreds of occasional authors of research including many students who write graduation theses every year, and benefits from the energy generated by TS, which has also grown spectacularly over the past 3 decades. What can critical analysis of the situation reveal and suggest?

\subsection{Achievements}

If IS is seen as a scientific discipline in the traditional sense of the word, i.e. a scholarly activity which seeks to explore reality with rigorous investigation methods and come up with facts and with theories having explanatory and predictive power which are continuously tested and replaced with better theories, it is difficult to speak of spectacular achievements. Models and theories have been developed to account for interpreting processes, some from within interpreting and some with inspiration from theories and findings in other disciplines, but none has been submitted to extensive testing as is the case of theories in established empirical disciplines, and factual discoveries have been modest and not convincing enough to win over the support of interpreting practitioners. This absence of spectacular achievements is neither surprising nor abnormal in view of the short history of interpreting research and of available resources (see the discussion later in this paper), but it has caused impatience among conference interpreting practitioners just as (as repeatedly stressed in the literature) a similar lack of spectacular findings has caused reservations if not hostility against the translation research community on the side of translation practitioners.

On the other hand, if IS is viewed as an academic activity in a wider sense without the stringent requirements of science in its traditional sense, it has achieved useful results. In particular, it has provided interpreter trainers with conceptual frameworks around which to structure their ideas and teaching 
activities. The very existence of an academic entity devoted to interpreting is also a social achievement with positive implications on the status of training programs and of professionals who graduate from such programs. These results may not be very important for conference interpreters, who found themselves historically in a rather privileged position from the start (see for instance Baigorri Jalón 2004). However, they seem to have had substantial implications for various forms of public service interpreting, including court interpreting and medical interpreting, as they have drawn the attention of public authorities in a number of countries to the need for training, both for interpreters and for users of their services (numerous examples can be seen in the Critical Link series published by John Benjamins and in papers collected in Hertog \& van der Veer 2006).

\subsection{Objective limitations}

5.2.1 The small size of IS: a quantitative limitation with qualitative implications

When considered holistically, one objective feature of Interpreting Studies which necessarily limits its effectiveness is its small size, both in the number of active researchers (currently about 50 worldwide who produce at least one publication every two years) and in the number of studies conducted each year. Replications and quasi-replications are necessary in order to test and improve theories and methods; without them, general progress is slow. Research on written translation suffers from a similar limitation, though its size is much larger than that of IS.

The small size problem is compounded by other factors. The first is the existence of a disproportionately large publication space. With more than 20 Translation journals willing to publish papers about interpreting, several TS conferences with proceedings every year and other collective volumes, there is little competition for IS authors. Actually, it is often editors who have problems finding enough papers for their journals or other publication projects. As a result, being strict about quality is not always possible.

Another problem associated with the small size of the IS community is that most active researchers know each other rather well and many establish personal links. As a result, it is not always easy to act objectively as referees in peer reviewing (where specific comments or writing style often identify the 'anonymous' reviewer) and in doctoral and other committees. Players are bound to play the game by inter-personal social rules at least as much as by academic norms. In such a small society, criticism, however necessary as a 
quality assurance mechanism, can be perceived by fellow researchers as a lack of support if not as unfriendly, and is therefore often self-inhibited. Time and again, I have seen colleagues refrain from uttering in public or writing officially what they said in private about a particular study or $\mathrm{PhD}$; time and again, I have heard colleagues say that a given doctoral study is not up to standards, but failing the student would not be socially acceptable vis-à-vis the supervisor; time and again, I have seen colleagues accept decisions and action which they thought were not the best in terms of research so as to avoid offending someone or generating a conflict. In larger disciplines with thousands of active researchers, this 'within the family' restraint is probably less of a problem.

Note that with the integration of PSIR into IS, the field is growing considerably; it may extend further and become richer if and when more investigators of Signed Language Interpreting join.

\subsubsection{Qualitative weaknesses}

IS literature can be conveniently classified in four categories:

a. Professional literature: this includes narratives, descriptions of and reflection on working conditions, interpreting strategies, interpreter training, interpreter status, interpreter associations, professional ethics, etc. In order to be effective, such literature needs to be clear, convincing and perhaps informative, but does not have to abide by academic or research norms.

b. Academic literature of the liberal arts type (henceforth Liberal Arts Paradigm or LAP - see the relevant Research Issues page on the EST website www.est-translationstudies.org): texts in this category comply with the norms of academic writing in the humanities. They include citations, refer to theories and are considered adequate or good depending on the intellectual work and knowledge of the literature that they reflect and on the quality of their rhetoric, on their innovative ideas, enlightening analyses, etc.

c. 'Scientific' literature in the traditional sense (developed initially from the tradition of the natural sciences and adapted and developed further within social sciences as well) complies with the relevant norms of academic writing and depends less on rhetoric and more on strict, systematic, cautious, logical, objective use of data. Such literature will be referred to as reflecting the Empirical Science Paradigm or ESP (see the relevant pages in the Research Issues section of the EST website).

d. Extra-paradigmatic academic texts (EPAT): academic literature also includes many essays, reviews, analyses and didactic texts which are directly related to academic issues but which are not research texts in either a LAP or ESP sense. This essay could be classified in the EPAT category. 
Many texts on interpreting published in the 1950s, the 1960s and the 1970s, including handbooks and articles in Translation journals, are clear and convincing presentations of situations and ideas and have value in making sense of professional reality and in providing guidance to students and beginners. However, their prescriptive nature and the lack of links with the existing literature, of sufficient theoretical work and of strict research methods aiming at finding relevant data and testing ideas do no qualify them as good academic texts, be it in the liberal arts paradigm or in the empirical science paradigm. They might best be classified in the professional literature category and are not of much concern here, not because they are not part of IS (they share the same journals as other categories texts), but because the present analysis focuses on academic texts.

The main problem in the academic literature of IS is that too many of its publications do not comply with academic norms other than academic writing. Frequent problems include weak or inexistent references to the existing literature on the subject, misrepresentation of the literature when it is quoted (Gile 1999 illustrates the nature of the problem and its potential consequences), incorrect comprehension and use of concepts from adjacent disciplines when their theories are imported, invalid and otherwise inadequate research designs with respect to piloting, to sampling, to the choice of variables, to quantification procedures, to experimental tasks, to other experimental conditions, unsubstantiated assertions, overgeneralizations and inferencing errors. For reasons which can easily be understood from the previous section, examples will not be given here, but evidence is easy to find in the reports of doctoral defence committees and in some published book reviews. Incidentally, these qualitative weaknesses are shared by TS in areas other than interpreting. Pym speaks of the "notoriously inept standards of much of the empirical research in our field" (1994:147) and Toury of the poor quality of theory in TS (1980:26, 80, 1995:262). (See also Toury 1991, Jääskeläinen 2000, Gile \& Hansen 2004, Chesterman 2006.)

These frequent weaknesses may be one important reason why researchers from adjacent disciplines, in particular cognitive psychology, seldom quote the interpreting literature and do not really cooperate with interpreting researchers in spite of the initial interest shown by renowned psychologists and sociologists in the 1970s, and later in the 1990s (see Gerver \& Sinaiko 1978, Danks et al. 1997, Englund Dimitrova \& Hyltenstam 2000). 


\subsection{Explaining the weaknesses}

Such weaknesses in the literature are thought-provoking: authors of publications on interpreting are generally highly articulate, educated and motivated individuals who, in the course of their professional work as interpreters, demonstrate that they can grasp complex ideas rapidly and reformulate them on the spot in a way acceptable to specialized audiences. Problems in their research are not likely to be caused by insufficient intellectual or linguistic abilities; explanations must be sought elsewhere.

\subsubsection{Environmental factors}

In established academic disciplines, research is done by 'professional' researchers who devote most of their time to research and to academic teaching and whose professional career depends on the quality and quantity of the research they produce. Most of them work in academic centres organized to facilitate research with well stocked libraries and travel grants. This is also the case of some TS centres, especially those which focused on literary issues and cultural issues. In IS, up to well into the 1990s, virtually all researchers were practicing interpreters who had to share their time between well-paid interpreting, unpaid research and relatively poorly paid training work. Training programs prided themselves on their professional orientation as opposed to an academic one, and, with a few exceptions, little if anything was done in terms of infrastructure to facilitate research. The very small number of IS researchers worldwide has also been pointed out earlier in this paper. The situation has improved markedly over the past decade or so, if only because of increased academization of interpreter and translator training programmes in many countries and thanks to the integration of interpreting research into TS.

Another environmental issue often mentioned in the literature is the reluctance of interpreters to serve as subjects for investigation, which makes data collection problematic. It is difficult to conduct initial experiments with large enough samples of professionals, not to speak of replications.

The third major environmental issue is the difficult access to naturalistic data, not only because of the interpreters' reluctance to be recorded and scrutinized, but also because many interpreted meetings are confidential. Recent developments have generated new possibilities with respect to naturalistic data. Many speeches and their interpretations are broadcast over radio, TV and internet sites and thus become available for investigation. 


\subsubsection{Human factors}

Not quite independent from environmental factors, but perhaps more fundamental, are human factors. Firstly, most IS researchers have not been trained in research through research methods courses and hands-on supervised exercises over the years as is the case of researchers in empirical disciplines. Neither have they been introduced to academic research of the liberal arts type through seminars and theoretical discussions around academic papers. Most of the first-generation authors in the 1960s and 1970s were self-made academics writing in an open, uncharted publication space with little if any peer-reviewing - their status of experienced and prestigious professionals gave them enough credibility to have their ideas published. In contrast, most TS pioneers in the 1970s were genuine academics trained in literary studies.

Most second-generation IS authors (in the 1980s) had a similar background as the first-generation authors, but they had a model, namely texts produced by their predecessors during the previous decade. In their form, their texts read like academic texts, but the underlying approach was not anchored in a scholarly tradition, and as mentioned earlier, the dominant paradigm at that time was deliberately hostile to a number of central aspects of empirical research as practiced in psychology and linguistics, and it did not refer to theories from the humanities either.

When, in the 1990s, the prevailing attitude eventually changed into aspirations for more 'scientific' research, the foundation for such research was still lacking. Some members of the CIR community became interested in empirical research as found in established disciplines, with sometimes relatively complex design. However, in such research more than in basic descriptive or exploratory investigations, errors in design and inferencing have particularly adverse effects on the overall quality on the studies at hand and their outcome. The problem was compounded by the facts that such colleagues were often experienced and successful interpreters and interpreter trainers, perhaps with the self-image which comes with such success, and that they could not afford (and perhaps were not willing) to take time off their interpreting and training activity to invest in studying research methods thoroughly in hands-on courses with younger students.

One could have hoped that the interaction with scholars from established empirical disciplines would help improve the situation by providing useful criticism to IS researchers. This does not seem to have been the case, except for students who prepared their theses and dissertations under the supervision of researchers from cognate disciplines. Apparently, little or no criticism was offered to more experienced members of the IS community, again probably 
for reasons which have to do with social interaction between invited outsiders and inviting personalities who have a high status in their community. This also applies to doctoral committees and could well challenge the credibility of doctoral qualifications of many of us in the eyes of critical outsiders.

In some universities, the situation has been improving gradually. Instructors now require more rigorous work from their students than in the past and there is some guidance from colleagues from other disciplines. Moreover, there is now a new generation of IS scholars who started doing research as students as part of their graduation requirements before they became successful interpreters and/or trainers and before they graduated out of student's status. The quality of research by these new members of the community is often better than that of previous generations and bodes well for the future.

\section{IS and TS}

The fact that interpreting research and translation research initially took different paths is easy to understand. Firstly, conference interpreting investigators focused almost exclusively on the interpreting process, as the challenges practitioners had to face were essentially cognitive. In research on written translation, cognitive issues were not in the investigators' minds, but equivalence problems linked to language and culture were, and the fact that TS as a discipline started within literary and cultural studies added emphasis to the cultural dimension which conference interpreters did not see as particularly important except in a few countries such as Japan. Secondly, while TS arose from within literary studies, as explained earlier, pioneers of research into interpreting had no academic background and wished to establish a discipline of their own without outside interference.

The increasing contacts with TS over the past decade or so have influenced IS (see below). Note however that, as illustrated inter alia by citations as an indicator (see Gile 2006), it does not look as if translation research has received much influence from interpreting research.

\subsection{Social aspects}

Perhaps the most important implications of the close links which have developed between translation research and interpreting research on the latter are social. Previously, as an independent and strongly profession-oriented movement, IS was perceived by both insiders and outsiders as not quite academic. Now it seems to be commonly viewed by members of the TS community as part of the larger academic discipline of Translation Studies. In such a social 
group, membership is made legitimate by one's academic status, not by one's professional practitioner's status. In Interpreting Studies, this is a dramatic change from the past, where the authors' high professional standing was sometimes used as a shield against academic criticism of their research.

\subsection{Foci}

The central concerns of conference interpreting research and translation research remain to a large extent different: in the former, the main challenges are associated with the very feasibility of interpreting, whereas in the latter, feasibility is assumed and the main challenges are associated with translation choices and their effects. However, this leaves room for common ground, including training-related issues, economic and professional issues, quality measurements, the Translator's understanding of the Source Text, language interference, linguistic description of the Translation products, history, etc. (see for example Schäffner 2004).

When, in the late 1990s, research into public service interpreting started to be considered a part of Interpreting Studies, this widened and strengthened the interface between translation research and interpreting research. In public service interpreting, issues around the interpreter's choices have been more central than feasibility as such. Inter alia, fidelity issues, particularly salient in court interpreting, arise from a conflict between communicational norms and the specific expectations from judicial actors. Ethical issues are often unavoidable in situations where administrative or otherwise 'official' logic seems to be at odds with difficult personal situations experienced by individual clients of the interpreter and with expectations of such clients who are looking up to the interpreter to help rather than serve as a neutral conduit (see the papers in Hertog \& van der Veer 2006 and in Janzen 2005). Interpreters are often members of the ethnic community to which such clients belong and frequently suffer from a relatively low social status both as interpreters and as members or these communities, which leads to sociological awareness as well. While awareness of sociological issues in the world of translation studies has a different, more intellectual origin, this creates further common ground.

\subsection{Theories and paradigms}

Among the first theories and modes developed from within interpreting research, Chernov's Probability Prediction Model (see Chernov 2004) was essentially cognitive, addressed simultaneous interpreting issues and was not very relevant to written translation research. Seleskovitch's Théorie du sens 
was also cognitive, but its very general nature made it suitable for adoption in the training of translators as well, and it became popular in the Frenchspeaking world. Subsequent interpreting theories and models from within conference interpreting research were more sophisticated but less relevant to research into written translation. Overall, there was little interaction between translation theories and interpreting theories until the 1990s, though a few interpreting research authors such as Stenzl and Pöchhacker referred in their writings to theories developed by translation scholars.

Since the 1990s, the influence of translation theories in interpreting research can be detected more clearly. Toury's ideas on the central role of norms have come to influence IS - see for instance Shlesinger 1989b, Schjoldager 1995, Ozben 1999. The influence of TS could also be a factor in the growing role in IS of text linguistics, relevance theory, corpora, and most recently sociological theorizing of Translation around Bourdieu's ideas (see for example Inghilleri's and Mason's papers in Schäffner 2004) and socio-cultural theorizing (Pym et al. 2006).

Perhaps more than individual theories, the strongest scholarly effect of interaction between translation research and interpreting research resides in the recent development of the Liberal Arts Paradigm in IS. Despite the existence of ESP work on written translation, as illustrated in particular by work coordinated by Sonja Tirkkonen-Condit (see Tirkkonen-Condit 1991) and Gyde Hansen (1999, 2002), LAP dominates in TS (evidence is overwhelming in citations, virtually all of which refer to theories, ideas and opinions and very few to empirical findings, tests of theories or research methods - for an introduction to citation analysis in TS, see Gile 2006), and seems to be attracting an increasing number of IS investigators, in particular in connection with sociological issues. In the late 1980s and early 1990s, there was a struggle between professional literature and ESP. Regular interaction with translation research within TS has changed this by introducing LAP as a central paradigm in the game.

\subsection{Research expertise}

As was mentioned earlier, some TS scholars who came from literary studies had received academic training as researchers in their discipline which they could apply to TS as well, at least as long as they remained within the scope of their 'native' discipline - when they ventured into other areas, and in particular empirical research, their expertise was sometimes irrelevant to a large extent. On the other hand, most IS scholars did not venture into literary studies-related areas. As a result, interaction between translation researchers 
and interpreting researchers has not raised the level of expertise of the latter to a significant extent. However, it did strengthen the social position of the relevant IS leaders, as they were acknowledged as leaders by a larger community - without being peer-screened for actual expertise. The phenomenon may have been amplified by the fact that interpreters, especially conference interpreters, are often good speakers with a strong personality, which may have led to a greater impact on a mixed audience of translation researchers and interpreting researchers than presentations by less talented speakers might have produced.

In other words, interaction between TS and IS may have actually made the status legitimacy issue of IS leaders more problematic that it was previously by amplifying the social influence without having added much in terms of quality control.

\section{Prospects and suggested directions}

From a small, profession-oriented, independent movement, IS has developed into a discipline within Translation Studies. From a narrow focus on conference interpreting processes and training, it has evolved to encompass many professional settings and categories of interpreting and many cognitive, linguistic, psychological and social aspects of interpreting. From prescriptive, anecdote- and introspection-based publications, it has widened its scope to include studies in line with the norms of empirical disciplines and studies which follow more theoretical disciplines. From an exclusively practicinginterpreter membership, it has evolved towards a mixed membership of practicing interpreters and academics.

Academically speaking, all these developments are positive, although they have brought some pitfalls along. In order to maximize their positive impact, the following suggestions for colleagues in charge of policy, training and supervision in IS might be helpful:

1. Encourage two-way interaction between translation research and interpreting research to maximize cross-fertilization. This would mean in particular endeavouring to show translation scholars that at least part of the research devoted to interpreting is relevant to their own research both because it investigates phenomena they are interested in and because the different viewpoints could help them triangulate in their perception of translation. Such cross-fertilization is helped by the participation of interpreting researchers and translation researchers in the same doctoral schools, but also by the integration of components of interpreting theory in translation theory courses, and especially by curiosity about all aspects of TS. All of them are legitimate, 
and there is something to be learned when seeking to understand all concerns and methods.

2. Be (realistically) humble about our research expertise. If we accept the idea that we are being asked to judge and guide other people's research while it is by no means clear that we are as qualified to do so as our titles and position in the TS community suggest, we may be more cautious in what we say, seek the help of experts whenever we can and generally continue to learn as we go along rather than think of ourselves as masters.

3. Make members of the community aware of fundamental differences between LAP and ESP. Whether one views them as two distinct paradigms or as two poles in a continuum does not matter. What is important is that in some ways, they explore reality and write about it in different ways, and this has generated communication problems between scholars (see for example the exchange between Pöchhacker and Gile in Schäffner 2004) and, more seriously, some confusion in the minds of younger colleagues under training; these problems can be addressed by awareness-raising.

4. When refereeing, assessing research work and supervising students' research, focus on rigorous thinking and on careful, evidence-based inferencing which, more than specific research methods and techniques, are at the very core of the 'scientific method'. The best way to proceed is probably through critical reading exercises and through the exchange of mutual constructive criticism. As explained earlier, socially, this is a difficult exercise, and it is tempting to make oneself popular by offering compliments only. However, training students, colleagues and ourselves to be rigorous in this way will put us in a better position to improve research across the board.

\section{References}

Note: the list of references has been kept deliberately short with a mainly illustrative function. Many more references can be found for further discussions in the lists of references found in each of the items listed below.

BAIgORRI JALÓN, Jesús. (2004) De Paris à Nuremberg: Naissance de l'interprétation de conférence. Cited from its French translation by Clara Foz. Ottawa: Les Presses de l'Université d'Ottawa.

Bersani Berselli, Gabriele, Gabriele Mack \& Daniela Zorzi (eds.) (2004) Linguistica e interpretazione. Forli: Biblioteca della Scuola Superiore di Lingue Moderne per Interpreti et Traduttori.

Chesterman, Andrew. (2006) Andrew Chesterman's presentation on research skills acquisition, in the 'Ljubljana colloquium on Research Skills' page on the EST site. 
CHERnOv, Ghelly. (2004) Inference and Anticipation in Simultaneous Interpreting. Edited with a critical foreword by Robin Setton and Adelina Ivanova. Amsterdam/Philadelphia: John Benjamins.

Collados Aís, Ángela; E. Macarena Prada Macías; Elisabeth Stévaux \& Olalla García Becerra (eds.) (2007) La evaluación de la calidad en interpretación simultánea: parámetros de incidencia. Granada: Editorial Comares.

DANKS, Joseph; Gregory Shreve; Stephen Fountain \& Michael McBeath (eds.) (1997) Cognitive Processes in Translation and Interpreting. Thousand Oaks, London \& New Delhi: Sage Publications.

Englund Dimitrova, Birgitta \& Kenneth Hyltenstam (eds.) (2000) Language Processing and Simultaneous Interpreting. Amsterdam/Philadelphia: John Benjamins.

GARZONE, Giuliana \& Maurizio Viezzi. (2002) "Introduction.” In: Garzone, Giuliana \& Maurizio Viezzi (eds.) 2002. Interpreting in the 21st Century: Challenges and Opportunities. Selected papers from the first Forli conference on Interpreting Studies. Amsterdam/Philadelphia: John Benjamins. pp. 1-11.

GERVER, David \& H. Wallace Sinaiko. (1978) Language interpretation and communication. New York: Plenum.

GILE, Daniel. (1988) "Les publications japonaises sur la traduction: un aperçu." Meta 33:1. pp. 79-89.

GILE, Daniel. (1999) "Use and misuse of the literature in interpreting research." The Interpreter's Newsletter 9. pp. 29-43.

GILE, Daniel. (2006) "Linterdisciplinarité en traductologie: une optique scientométrique." In: Kasar, Sündüz Öztürk (ed.) 2006. Interdisciplinarity on Translation. Istanbul: İsis. pp. 23-37.

GILE, Daniel \& Gyde Hansen. (2004) "The editorial process through the looking glass.” In: Hansen, Gyde; Kirsten Malkmjær \& Daniel Gile (eds.) 2004. Claims, Changes and Challenges in Translation Studies. Amsterdam/Philadelphia: John Benjamins. pp. 297-306.

GRAN, Laura \& John Dodds (eds.) (1989) The theoretical and practical aspects of teaching conference interpreting. Udine: Campanotto Editore.

GRAN, Laura \& Christopher Taylor (eds.) (1990) Aspects of Applied and Experimental Research on Conference Interpretation. Udine: Campanotto Editore.

HALE, Sandra. (2006) "Themes and methodological issues in Court Interpreting research." In: Hertog, Erik \& Bart van der Veer (eds.) 2006. pp. 205-228.

Hansen, Gyde (ed.) (1999) Probing the Process in Translation: Methods and Results. Copenhagen Studies in Language 24. Copenhagen: Samfundslitteratur

HAnsen, Gyde (ed.) (2002) Empirical Translation Studies: Process and Product. Copenhagen Studies in Language 27. Frederiksberg: Samfundslitteratur 
Hertog, Erik \& Bart van der Veer (eds.) (2006) Taking Stock: Research and Methodology in Community Interpreting. Special Issue of Linguistica Antverpiensia $5 / 2006$.

JÄÄSKELÄINEN, Riitta. (2000) "Focus on Methodology in Think-aloud Studies on Translating." In: Tirkkonen-Condit, Sonja \& Riitta Jääskeläinen (eds.) 2000. pp. 71-82.

JANZEN, Terry. (2005) Topics in Signed Language Interpreting. Amsterdam/Philadelphia: John Benjamins.

MASON, Ian. (2006) "Ostension, inference and response: analysing participant moves in Community Interpreting dialogues." In: Hertog, Erik \& Bart van der Veer (eds.) 2006. pp. 103-120.

ÖZBEn, R. Tunç. (1999) A critical re-evaluation of the target-oriented approach to interpreting and translation. Istanbul: Marmara University - Center for Foreign Language Teaching and Research.

PöchHACKer, Franz. (1995) “Those Who Do...': A Profile of Research(ers) in Interpreting." Target 7:1. pp. 47-64.

PÖchHACKer, Franz. (2004) Introducing Interpreting Studies. London \& New York: Routledge.

PÖCHHACKER, Franz \& Miriam Shlesinger. (2002) The Interpreting Studies Reader. London \& New York: Routledge.

PyM, Anthony. (1994) "Ideologies of the Expert in Discourses on Translator Training." Koiné 4. pp. 139-149.

PYM, Anthony, Miriam Shlesinger \& Zuzana Jettmarová (eds.) (2006) Sociocultural Aspects of Translating and Interpreting. Amsterdam/Philadephia: John Benjamins.

RuDVIN, Mette. (2006) "The cultural turn in community interpreting. A brief analysis of epistemological developments in Community Interpreting literature in the light of paradigm changes in the humanities." In: Hertog, Erik \& Bart van der Veer (eds.) 2006. pp. 21-41.

SCHÄFFNER, Christina (ed.) (2004) Translation Research and Interpreting Research. Traditions, Gaps and Synergies. Clevedon, Buffalo \& Toronto: Multilingual Matters.

SCHJOldaGer, Anne. (1995) "An exploratory Study of Translational Norms in Simultaneous Interpreting: Methodological Reflections.” Hermes 14. pp. 65-87.

SELESKOVITCH, Danica. (1984) "La compréhension d'une pensée à travers son expression." In: Seleskovitch, Danica \& Marianne Lederer. Interpréter pour traduire. Paris: Didier Erudition. pp. 294-308 (reprint from Multilingua 1.1.82)

SHLESINGER, Miriam. (1989a) Simultaneous Interpretation as a Factor in Effecting Shifts in the Position of Texts on the Oral-Literate Continuum. Unpublished MA thesis. University of Tel-Aviv. 
SHLESINGER, Miriam. (1989b) "Extending the Theory of Translation to Interpretation: Norms as a Case In Point." Target 1:1. pp. 111-116.

STENZL, Catherine. (1983) Simultaneous Interpretation - Groundwork towards a Comprehensive Model. Unpublished MA thesis. University of London.

TIRKKONEN-CONDIT, Sonja (ed.) (1991) Empirical Research in Translation and Intercultural Studies. Tübingen: Gunter Narr.

TiRKKONEN-CONDIT, Sonja \& Riitta Jääskeläinen (eds.) (2000) Tapping and Mapping the Processes of Translation and Interpreting. Amsterdam/Philadelphia: John Benjamins.

TOURY, Gideon. (1980) In search of a theory of translation. Tel-Aviv: The Porter Institute for Poetics and Semiotics.

TOURY, Gideon. (1991) "Experimentation in translation studies: prospects and some pitfalls." In : Tirkkonen-Condit, Sonja (ed.) pp. 45-66.

TOURY, Gideon. (1995) Translation Studies and Beyond. Amsterdam/Philadelphia: John Benjamins.

VALERO-GARCÉS, Carmen. (2006) "Community interpreting and linguistics: A fruitful alliance? A survey of linguistics-based research in CI." In: Hertog, Erik \& Bart van der Veer (eds.) 2006. pp. 83-101.

\section{Internet Websites:}

CIRIN: www.cirinandgile.com

European Society for Translation Studies: www.est-translationstudies.org 